\title{
Exploring the Factors that Affect the Choice of Destination for Medical Tourism
}

\author{
Harsimran Gill, Neha Singh \\ California State Polytechnic University, Pomona, USA. \\ Email: nsingh@csupomona.edu \\ Received April 13 ${ }^{\text {th }}, 2011$; revised May 29 ${ }^{\text {th }}$ 2011; accepted June 20 2011.
}

\begin{abstract}
Medical Tourism has become one of the latest trends in the tourism industry which has been and has the potential to continue growing exponentially every year. More travelers than ever before are now travelling abroad to get high quality medical treatments for less cost. The purpose of my study is to explore the interest in US travelers in medical tourism. Results from the survey indicated that "competent doctors", "high quality medical treatment facility", and "prompt medical treatment when needed" where the top three factors before deciding whether or not to take a trip abroad. The results will be useful to businesses that are either directly or indirectly involved with this industry, such as insurance companies, credit card companies, travel agencies, hotels, food and beverage companies, medical facilities and services, and spas.
\end{abstract}

Keywords: Medical, Health, Tourism, Medical Tourism, Destination Choice, Tourism Industry, Health Tourism

\section{Introduction}

Medical tourism has reformed the traditional health-care industry and has set a new benchmark for every country around the globe. More travelers than ever before are now travelling abroad to get high quality medical treatments for less cost, which includes treatments such as general surgery, transplant surgery, cancer treatment, stem cell therapies, dental implant, facial implant, and liposuction, just to name a few. Both developed and developing countries are considering investing their infrastructures in this infant industry to stay on top of the aggressive competition.

Medical tourism as a niche market has emerged from the rapid growth of what has become an industry, where people travel often long distances to overseas countries to obtain medical, dental and surgical care while simultaneously being holidaymakers, in a more conventional sense [1]. This new trend of medical tourism is different from the traditional model. In the traditional model, patients travelled from less developed nations towards more developed nations where treatment quality would be much advance and significantly better. However, in the current medical tourism model, there is a flow of patients in both directions, i.e. from developed to developing and vice-versa [2,3].

The rise in medical tourism has opened up opportuni- ties for many businesses. A report by Deloitte Center for Health Solutions estimates that by 2017, about 15.8 million US patients will receive care outside of the country, resulting in a potential "opportunity cost" to US clinics of about $\$ 373$ billion [4]. Among others there are few specialized medical travel agents, like MedRetreat, can choose from a menu of 183 medical procedures from seven different countries: India, Thailand, Malaysia, Brazil, Argentina, Turkey, and South Africa. Medical Tours International has sent more than 1300 patients in 2005 to abroad and has got medical personnel to assist patients with trip planning and travel decisions. Another example would be PlanetHospital, California based, that screens providers to ensure quality of care and assists in connecting patients to international health care providers. They have various steps in initial screening process: whether the patient is in proper condition to travel, choosing appropriate physician and destination, digitalize records and send them to physicians in destination country, arrangement of conference call between potential patient and physician from foreign country. Also, nearly two-thirds of physicians who work for PlanetHospital have either fellowships with medical societies in the US or UK, or are certified for a particular specialty by a medical board [5].

The purpose of my study is to explore the interest of 
US travelers in medical tourism. Students from a western university participated in data collection. The study will offer insights into factors that people might consider when addressing their medical needs in the future. The results could be useful to businesses that are either directly or indirectly involved with this industry, such as insurance companies, credit card companies, travel agencies, hotels, food and beverage companies, medical facilities and services, and spas. Moreover, in this era of globalized health care, businesses can survive by understanding the needs of this market, and by incorporating the demands of potential patients.

\section{Literature Review}

\subsection{Medical Tourism}

In order to grasp the notion of "medical tourism", "health tourism", or "wellness tourism", it is essential to comprehend the definition and the context under which these terms are used interchangeably. "Wellness tourism is the sum of all the relationships and phenomena resulting from a journey and residence by people whose main motive is to preserve or promote their health. They [people] stay in a specialized hotel which provides the appropriate professional know-how and individual care. They require a comprehensive service package comprising physical fitness/beauty care, healthy nutrition/diet, relaxation/ meditation and mental activity/education" [6]. According to Bookman and Bookman [7], "the sale of high-tech medical care to foreigners has come to be called medical or health tourism". Tabacchi defines health tourism as "any kind of travel to make yourself or a member of your family healthier" [8]. Although some writes have used the term "medical tourism" to incorporate all forms of health-related tourism [9] it seems to be more useful to distinguish 'medical tourism' as one involving specific medical interventions [1].

Although there are various definitions and terms used to define the act of travelling abroad for medical purposes, but for this research a more holistic definition will be applied. "Medical tourism is the act of travelling abroad [across international borders] to obtain various types of health and wellness treatments" [10]. This definition will provide a comprehensible approach of the term medical tourism.

A study conducted in Swiss hotel groups revealed that guests visiting any particular country for medical reasons should be approached differently based on their expectations of visit, and their understanding of the terms "wellness" and "cure". So, if hotels around the world want to be ahead of competition, then they have to customize their marketing approach based which segment of tourists they are planning to capture: those who come for medical treatments or those who are travelling for pure relaxation [6]. Also, it implies that health policy makers must value these two distinct groups and work with tourism service providers to address the expectations of customers. Moreover, hotelier should design rooms, facilities and service environment to assure customer satisfaction of the highest level because it will help promote business and customers will recommend the hotel to others which will promote reputation and spread good wordof-mouth [11].

Another revolution in the traditional hotels segments is brought by "focused factories". According to Devon M. Herrick [5], "these are specialty clinics and hospitals where tasks and procedures have been streamlines for the highest efficiency”. In other words, developing countries have built and continuing on expanding hotels that can serve as medical clinics, so that patients feel that they are vacationing.

The exceeding demand of various products and services that may or may not be produced in a country has resulted in strong political and economic collaborations of nations all around the world. Today more and more countries are signing trade agreements to take advantage of lower labor and material costs, fewer tariffs and quotas, and reduced barriers. Keith Pollard, director of British Web site Treatment Abroad, told CNN that "he doesn't foresee a boom in medical tourism within the EU [European Union], he believes the new legislation will encourage patients to seek treatment abroad and help create a European health care market” [12].

The developing countries can take advantage of rising outsourcing opportunities in fields such as entertainment, telemedicine, distance learning, and travel services. Two major factors that are contributing towards these fields are raising income in developed countries and relatively low prices in developing countries [13]. It means as the income rises, people will have more disposable income and would like to purchase goods and services from countries that offer at relatively competitive prices. In other words, there is an inverse relationship between rises in income in developed countries that facilitates higher demand in developing countries [13]. According to Bookman and Bookman, "a country or specific facility may be able to achieve competitive advantage in the marketplace by leveraging various non-clinical factors, including proximity to target patients and the ease of travel between two locations" [7].

The convenience of travelling from one point to another can be promoted by top-notch infrastructure of developing countries. Usually when people think of India's local transportation system, they imagine jam-packed buses, poorly constructed roads, bullock carts and horse carriages, and hand-pulled rickshaws. While India is at- 
tempting to improve its transportation infrastructure, there are other countries such as Republic of South Korea, Taiwan, and Singapore who have successfully incorporated new infrastructure, new technology and developed human resources [14]. However John Connell, 2005, says that India has upgraded its technology, absorbed western medical protocols and emphasized low costs and prompt attention to become most important global destination. He goes about saying that while such situations have now radically changed but the perception of inadequacy remains [1].

\subsection{Benefits of Medical Tourism}

Cost is one of the foremost determinants for patients seeking care from hospitals in foreign countries. Often, surgeries in developing countries will cost just a fraction of what one might pay in the USA or the UK [10]. Along with cost savings, a patient can expect state-of-the-art technology that is same or even better than western standards [15]. As an example, India is one of the developing countries that have "capitalizing on its low costs and highly trained doctors to appeal to these medical tourists" [1]. There are various reasons due to which foreign hospitals charge less for treatments: lower labor costs, little to no third party involvement, transparency in package pricing, limited collaborations between health care facilities and physicians, and lower costs of malpractice litigations [5]. Also, price differential wars have resulted in immense competition among developing countries. India has significantly succeeded in capturing this segment of tourist because it has developed the capability to offer "bypass operations for about a sixth of cost in Malaysia" [1]. Along with the cost of treatments, medical tourists are seeking out for countries that have significantly less currency fluctuations. After Thailand's currency collapse in 1997, the Thai government focused its resources to attract medical tourist, especially for plastic surgery, to yield higher revenues [16]. When medical tourism was flourishing as an industry, dollar was relatively weak to other foreign currencies. However, the absolute differential in medical prices has been so large that adverse exchange rates have not been a major consideration for medical tourists from the US [17].

Although cost is main the determinant of decision making to travel aboard, but having to wait for longer periods to get a treatment in developed countries is making this transition happen quickly. Even for the countries where government health-care system is in place, like Britain and Canada, patients are reconsidering to get their treatments from their home countries. Also, it gives the opportunity for developed countries to "clear their backlog by sending patients to foreign countries for expedient care, at low cost, without expanding local capacity” [18].
In 2005, the waiting times for hip and knee replacement were 21.8 and 28.3 weeks, respectively, in British Columbia, Canada, in contrast to service within a few days of referral in most medical tourism destinations [19].

Moreover, cost can be of significant importance to those who do not have insurance. According to Sharon Reier (2004), about 38 percent of the uninsured and onequarter of those with insurance would travel abroad for care only if savings exceeds $\$ 10,000$. A research conducted by Oxford Analytica discovered that more than 45 million US citizens do not have health coverage and those who do they are not very satisfied with health-care services [20,21].

Another rationale for Americans to leave their comfort zone and travel to foreign countries is quality of health care. Many potential patients might think that cultural differences, mainly language and background, will make it difficult for them to communicate with their foreign health care service providers. However, the cultural barriers are reduced by having educated and English speaking staff physicians and nurses. American Medical Association (AMA) introduced set of guidelines for medical tourism that included proper follow-up care, letting the patients know about their legal rights, informed risks for surgical procedures, and information on long flights and vacation activities [16].

People are realizing that they can save money by combining health needs along with vacation desires. Several companies are emerging that provide bundled packages which include air fare costs, accommodations from airport to hotels, cost of surgery, room and board expenses in hotels, and local sight-seeing costs [10]. Often times, the surgeries are not very intrusive and has fast recovery time. "The principal hospital group in Singapore, Raffles, arranges airport transfers, books relatives into hotels and helps to arrange local tours" [1]. This shows that tourism industry along with needs of patients from developing countries resulted in creation of medical tourism.

The issue of privacy makes medical tourism more popular because no one prefers to be on the headlines of media. "Some medical procedures, such as sex changes, have become small but significant parts of medical tourism, especially in Thailand, where recuperation and the consolidation of a new identity may be better experienced at a distance from standard daily life" [1]. Furthermore, it means that unlike in US, patients personal medical records cannot be viewed by a third party [4].

Some procedures are not approved by the US government that makes developing countries an attractive opportunity to acquire such treatments [10]. Lee goes about explaining the importance of governmental support to enhance tourism industry especially for developing countries [22]. For example, Singapore Tourism Board (STB) 
launched two marketing campaigns: "Singapore Medicine' in 2003 and 'Uniquely Singapore” in 2005 that anticipated S\$30 billion earnings and attracting 17 million visitors by the year 2015. Another type of procedure that might not be offered in countries like Britain and US is abortion. However, countries such as India have fewer regulations that are seen as attractive options for couples who would prefer to get an abortion. Also, procedure such as "stem cell therapy for heart failure, unobtainable by many patients in industrialized countries, is available in the medical tourism marketplace" [18]. Some patients leave US to get treatments that are not approved by medical specialty societies, academic health centers, and the Food and Drug Administration. For example, a shark cartilage is not scientifically accepted cancer treatment in US However, patients travel elsewhere to get this treatment in hopes of getting better through any means [17].

People use credit cards for it provides a better means to fulfill immediate demands and needs that can be repaid later. It generates more flexibility for travelers to carry a credit card that acts as an international currency. According to Weaver [23], credit card companies like Visa is promoting the universal use of its cards with the catchphrase "It's everywhere you want to be". The use of credit cards provides the travelers with less concerns about arranging the money instantaneously, and hence give them more freedom and mobility to use the credit cards as needed in near future [23].

There have been various types of questions arising from different fields of study, and all of them focus on the privatization of health care that is being offered to medical tourist in developing countries compared to the type of service offered to poor people of that country. One researcher wrote that "ethics is not only a question of making up one's mind and following one's conviction. It is also a question of listening to other persons' perspectives and opinions, and perhaps convincing others if you are sure about your own opinions" [24]. India has been subject of question about health services offered to their citizens who have little to no access to basic health care and have high infant and maternal mortality rates [1].

The quality of health care is very important determinant right after price because people have this perception that if something is offered of lower cost, so they might not receive better quality. In order to address this problem, developing countries are hiring physicians that have internationally respected credentials as well as training from developed countries like US, Australia, Canada or Europe. At present there are more than 120 hospitals abroad that are accredited by the Joint Commission International (JCI), and 20 hospitals that are accredited by the International Standards Organization (ISO). More- over, some foreign hospitals are managed by affiliated US health care facilities like Cleveland Clinic and Johns Hopkins International [5]. JCI-accredited Wockhardt hospitals offer open heart surgeries for $\$ 8,500$ in India, as compared to $\$ 100,000$ in the US and $\$ 28,000$ in the UK [25]. According to Jesse McKinley [26], Americans have growing appetite for nips and tucks, and it was evident from 12 million procedures performed in 2008.

\subsection{Costs of Medical Tourism}

People are still pondering over usefulness and benefits of medical tourism because they do not have enough knowledge about this industry. So, various consulting and non-profit organizations are making an attempt to market their services for those who are seeking to travel across borders for health reasons [10]. The quality of these services will set apart one provider from another, and it will also give them a competitive advantage over one another. Also, in some of the extreme forms of such travel, like where patients require euthanasia are discouraged due to high expected risks in procedures [1].

There is a lack of communication between institutes from both developing and developed countries. As a result, if a person seeks medical treatment in developing country like India, then there is no way that US insurance company could communicate and arrange payment for the treatment considering that the procedure is covered in the US [10]. A lack of insurance portability discourages prospective clients to obtain treatment in developing country [7]. Among other procedures, cosmetic surgeries are not covered by insurance. As an example, a face-lift in Costa Rica costs about a third of that in the US, rather less in South Africa [1]. On the other hand, since 2006, there have been attempts made by the West Virginia legislation to provide financial rebates to state employees who seek health care at medical tourism destinations "including first-class flights for patients and a companion, plus recovery in a four-star hotel and other incentives like bonuses and sick leave" [12,18]. On the other hand, some insurance companies consider the shift of patients to get medical treatment abroad as an incentive because they will have to pay less. For example, United Group Programs in Boca Raton, FL, is saving its employers 50 percent of health care costs by cutting employee contributions to zero [12]. According to Josef Woodman [27], "several insurance companies have begun to pilot programs together for medical tourism. One of the first was Companion Global HealthCare, which is affiliated with BlueCross BlueShield of South Carolina. United Healthcare, Aetna, WellPoint and Health Net of California now have medical travel and medical tourism packages. They're mostly being covered through employers. It's very early to tell what the acceptance level is going to be, 
but those plans are in place” [27].

The lenient terms of litigation and poor justice system in developing countries makes it difficult for patients to earn their rights of undertaking legal proceedings [7]. One major problem with poor malpractice laws is lack of communication between the physicians from developing countries with that of developed countries. It has resulted in physicians from highly litigious nations to not endorse offshore treatments to their patients as they are afraid of putting their reputation at stake. Furthermore, consequences of adverse outcomes, even death in some cases, would be difficult to fight for in foreign courts as the patients of their families are asked "the claims would have to be adjudicated in a foreign court" [18]. There is hesitation from the perspective of a physician and a patient, which is why the medical tourism industry has not matured much.

There is also a possibility that the patient was not aware about some pre-existing health problems which were brought to surface either prior to or during treatment in foreign hospital. This could result in breach of contract from physicians' point-of-view because he or she was not aware about the condition [5].

Sometimes hindrances of obtaining follow-up care discourage patients to travel. If the patient undergoes a less intrusive surgery then chances of recovering soon increases, but if the surgery or treatment is complicated then there are more complicacies involved: mental, physical, and financial considerations [10].

Media has adequate power to stir mystification in the minds of travelers especially when they are considering going abroad for medical treatment or vacation. For example in 2003 when SARS outbreak appeared, media exaggerated on the disease that resulted in negative impacts on global tourism [28]. The 9/11 tragedy the Muslim countries had lost tourist because the fear grew in the minds of travelers. On February 14, 2005 Gulfnews.com reported that a manager of one of Malaysian hospitals has said "since 9/11 people started looking to the Eastern world for holidays and we are trying to capture a fraction of these people". Americans have seen enough of turbulence in foreign countries which has resulted in low confidence levels to travel abroad for medical treatments, like terrorists' assaults that killed many foreigners in New Delhi, drug wars in Mexico, and antigovernment demonstrations that stranded thousands of tourists at the Bangkok airport [17].

The differences in cultural backgrounds play an important role in tourists' decision making process. According to Law [29], media plays an important role in altering destination of choice more for Asians as opposed to Westerners. It becomes primary concern of tourism planners to address this topic prior to gaining confidence of Asian clients [29].

\section{Methodology}

An exploratory study was conducted to understand the factors that affect the choice of destination for medical tourism: tools used for researching information on medical tourism, sources to seek medical advice, factors considered important for seeking medical care outside of the US, and choice of destination country, which is explained in details under Data Analysis section. Data was collected using a survey method from a total of one hundred and ninety-four students. The participants were recruited from various disciplines at a western University. They were provided with a brief introduction of the term 'medical tourism' prior to handing out the survey.

The participants answered a 3 page survey sharing their opinions and beliefs on medical tourism. A classroom setting was chosen to administer the data collection process. A researcher was available to respondents for any questions.

The first few questions focused on respondent's profile and remaining were centered on various factors impacting their decisions for travelling abroad for medical tourism. The questions were adopted from previous studies exploring this topic $[10,30]$.

\section{Data Analysis}

\subsection{Respondent's Profile}

Figure 1(a) shows that my sample consisted of $46 \%$ males and $54 \%$ females. The sample was close to equal distribution between males and females. Hence, there is a good probability to get the point-of-view from both males and females and their understanding of medical tourism.

Figure 1(b) shows the age groups of the sample: 63\% were 21 - 23 years; $16 \%$ were 24 - 26 years; $15 \%$ were 18 - 20; and 6\% were 27 and above.

Figure 1(c) depicts the ethnicity of sample: $49 \%$ were Asian/Asian American; 22\% were Caucasian; 20\% Hispanic/Latino; 4\% were Middle Eastern; 3\% were Hawaiian/other Pacific Islander; and 2\% were African American. This shows that diverse ethnicities were represented in the sample.

Figure 1(d) shows that $88 \%$ of people travelled outside the US, while $12 \%$ didn't. In other words, majority of the sample have visited to place outside the US, and they might have fairly good experience of travelling abroad.

Figure 1(e) illustrates the average number of trips taken in a year: $69.6 \%$ took 1 - 2 trips; $25.8 \%$ didn't take any trip; $4.1 \%$ took 3 - 5 trips; and $0.5 \%$ took 5 or more trips. It shows that about 70 percent, or two-thirds of our sam- 


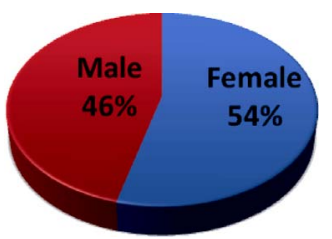

(a)

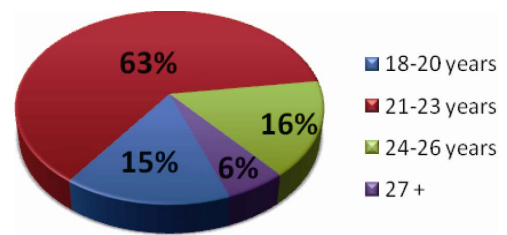

(b)

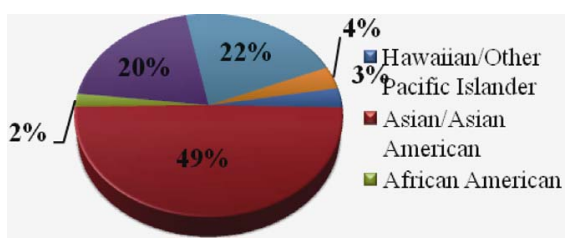

(c)

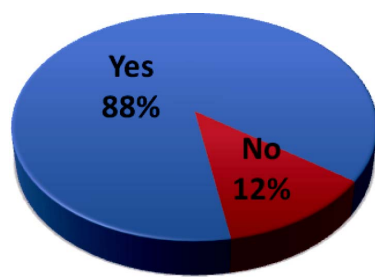

(d)

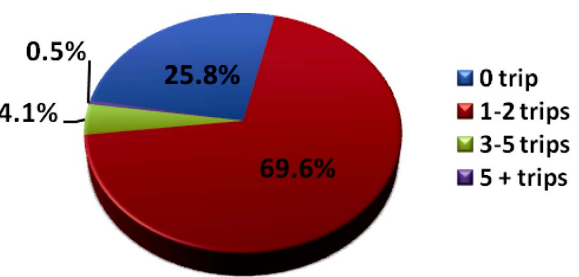

(e)

Figure 1. (a) Gender; (b) age group; (c) ethnicity; (d) travelled outside US; (e) average travel in a year.

ple, have taken at least one to five trips in this current year. Only 26 percent approximately did not travel this year at all. It is an interesting observation to see that even those who did not travel in this current had some valuable inputs regarding various factors and opinions on medical tourism.

\subsection{Tools Used for Researching Information on Medical Tourism}

Figure 2 illustrates on tools that the sample would use to research information on medical tourism: 73\% preferred online research; $10 \%$ relied on family physician's opinion; $8 \%$ relied on family and friends; $6 \%$ relied on testimonial of hospitals abroad; and 1\% each for printed brochures, videos providing tours, and television reports. The chart below shows that majority, seventy-three percent, picked online research as a very important tool. It could be because that the present generations of people are more technology savvy than older generations. Their second pick was getting recommendation from their primary physician in the US to decide which destination is better suited for their health needs. Although, this tool was about one-seventh of the previous one, but undoubted my sample seems to be concerned about the risks involved in foreign destination, so they preferred to seek advice from someone they trust. The third tool that they chose as important was asking friends and family if anyone has gotten any procedures done. The word-ofmouth seems like one of the important sources for seeking medical advice.

\subsection{Sources to Seek Medical Advice}

In Figure 3 the sample picked the sources that they

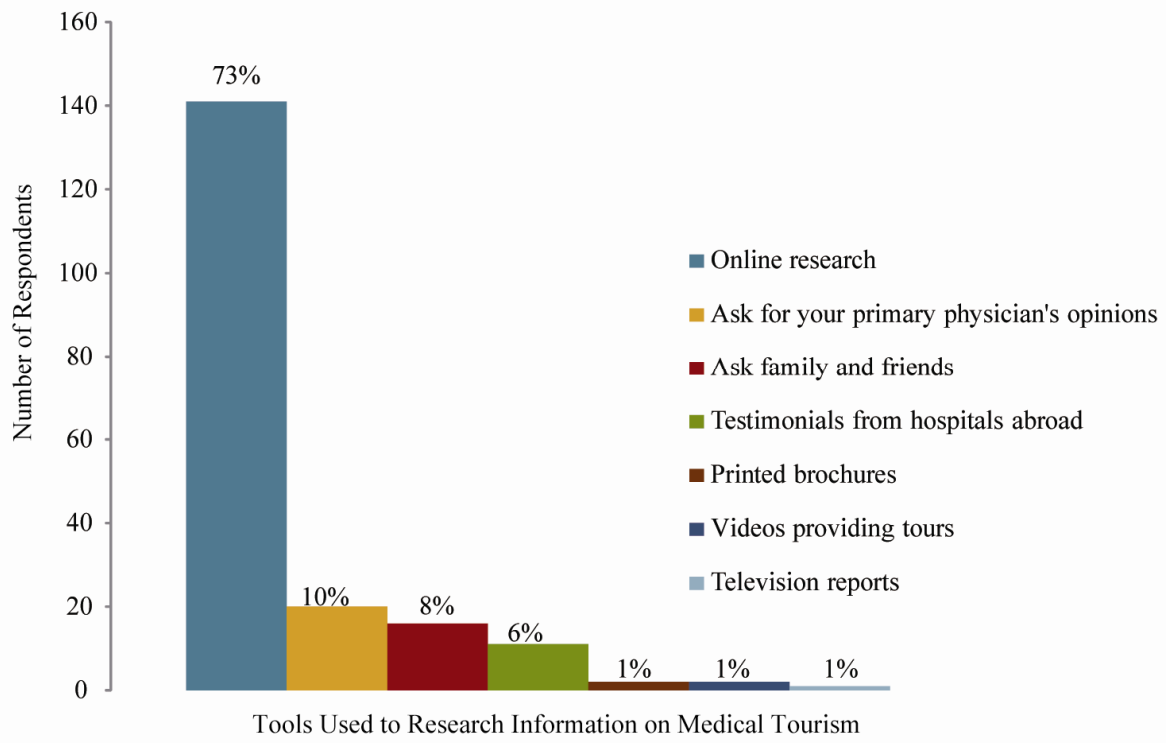

Figure 2. Preferences of background research. 


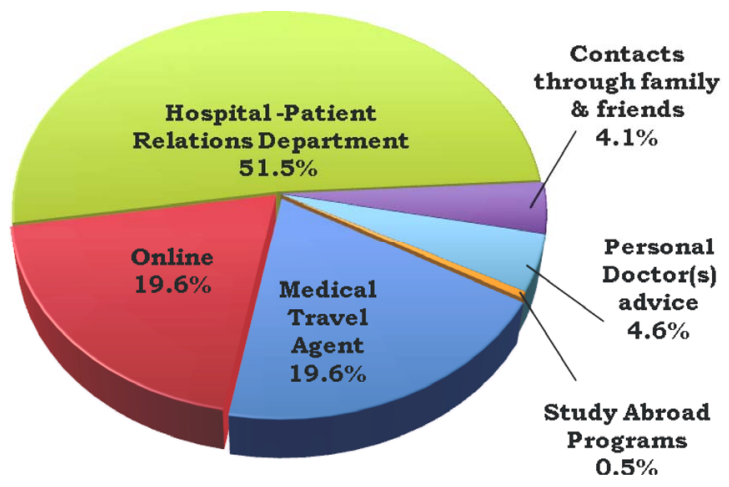

Figure 3. Sources to seek medical advice.

would consider to seek medical advice: $51.5 \%$ chose hospital-patients relation department abroad; $19.6 \%$ chose medical travel agent; $19.6 \%$ chose online research; $4.6 \%$ chose personal doctor(s) advice; $4.1 \%$ preferred to contact through family and friends; and $0.5 \%$ chose study abroad programs. So, clearly the top pick was hospitalpatient relations department in the foreign country followed by online research and medical travel agent. This chart could be helpful to businesses who are interested in learning where their perspective target market would seek advice for medical traveling.

\subsection{Factors Considered Important for Seeking Medical Care Outside the US}

Figure 4 tells us which factors the respondents seem to consider for seeking medical care outside the US: $65 \%$ focused on success rate for my-type-of-procedure performed; $17 \%$ looked at number of my-type-of-procedure performed; $10 \%$ focused on complication rate for mytype-of-procedure performed; $7 \%$ focused on the country of destination; and 1\% looked for relative ease of travel. The respondents were critically thinking about which

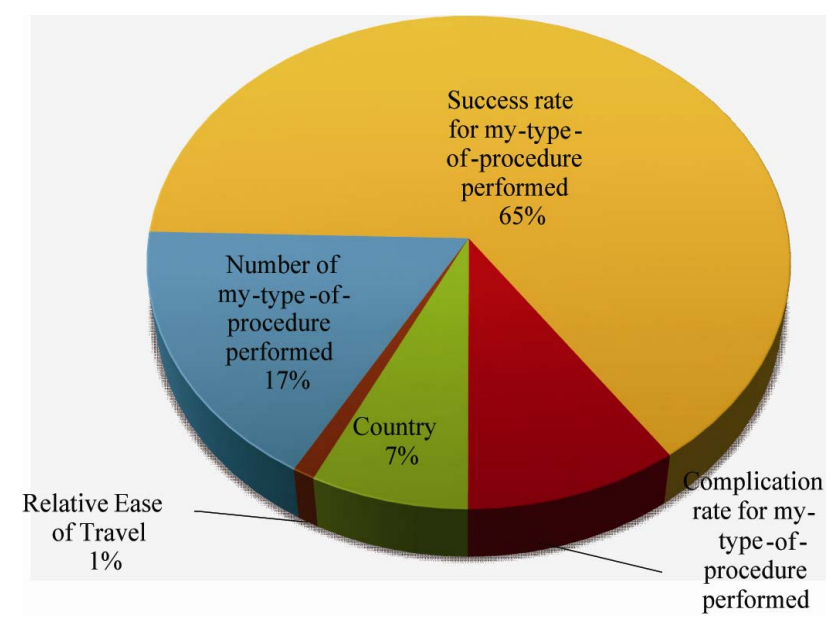

Figure 4. Factors considered important for seeking medical care outside the US. factor(s) would affect them and it is reflected in their responses.

\subsection{Choice of Destination}

Figure 5 shows the top choices of destination for travelling abroad for medical purposes were: Japan, South Korea, Singapore, Mexico, and India. The respondents picked the countries that they would consider if they had to make the decision of travelling for medical purposes. Frequencies were analyzed for this figure. Japan was ranked the highest by 82 respondents, $21 \%$ of the sample; South Korea was chosen by 40 respondents, $10 \%$ of the sample; Singapore was chosen by 31 respondents, $8 \%$ of the sample; Mexico was chosen by $24,6 \%$ of the sample; and India was chosen by 22 respondents, $6 \%$ of the sample.

\subsection{Factors Considered before Choosing Destination Outside the US}

Figure 6 shows the factors from most important being five, to least important being one. As it is displayed on the chart, medical facilities and services, local primary doctor's recommendation, and governmental policies and laws were among the most important choices. The two choices that were relatively important were hotels and food/beverage quality and general tourism supply.

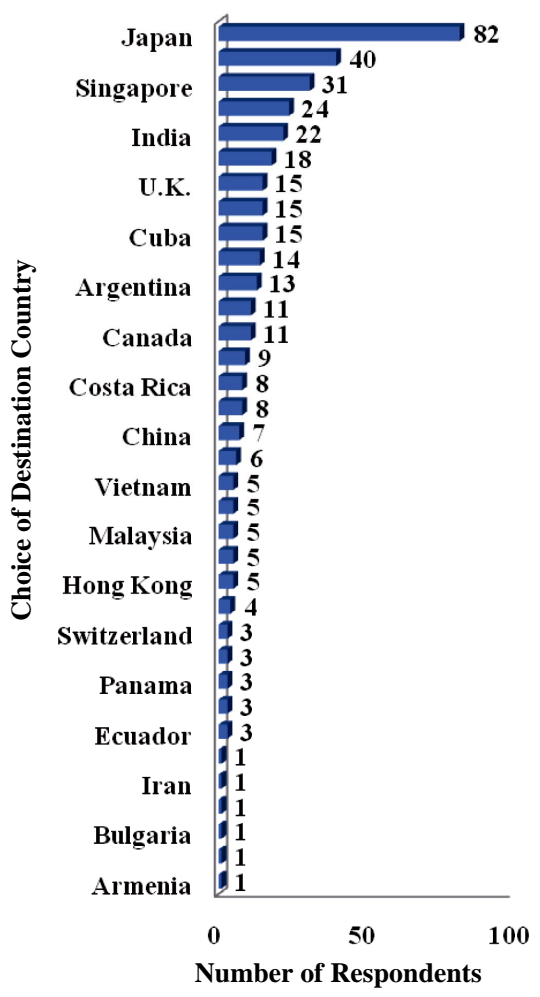

Figure 5. Choice of destination country. 


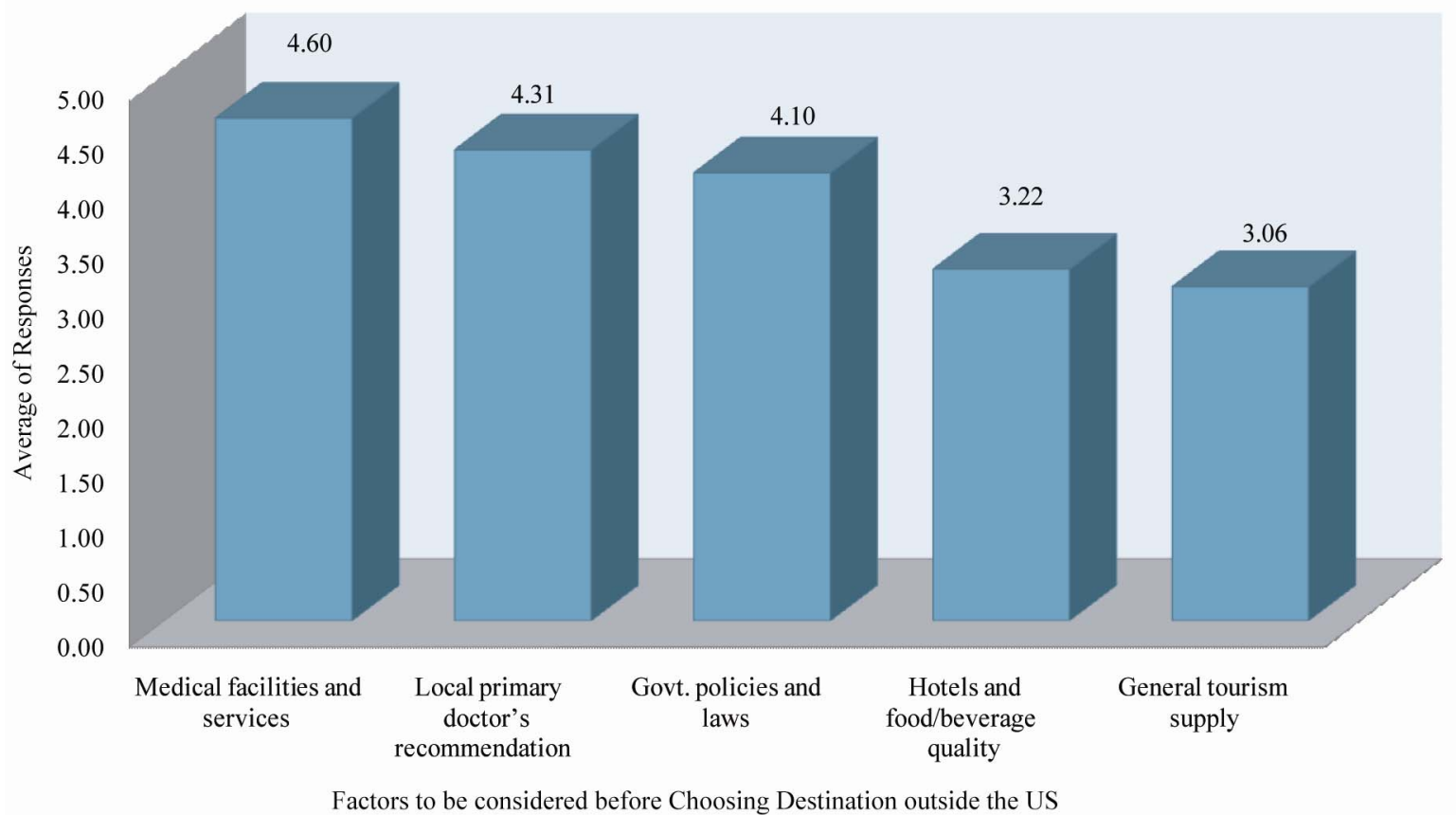

Figure 6. Factors considered before choosing destination outside the US.

\section{Limitations}

One of the major limitations of this study is its sample. Since, all of the respondents were students from various academic disciplines, so there is a probability that some of them did not have prior knowledge of the term 'medical tourism.' As a result, it is possible that they could not represent their opinions accurately. Although a brief introduction of medical tourism was mentioned prior to handing out the surveys, but it might not have addressed all the potential questions that respondents might have had at that time.

Another limitation of this study is its sample size. A total of 194 respondents participated in this study. It would be incorrect to relate the opinions delivered by the respondents to the total population. Even though the numbers of participants were fewer, but their opinions were well thought, and they clearly demonstrated critical thinking before making decision to travel abroad for medical purposes. Besides, the respondents could be potential tourists, but have not yet considered decisions of this nature. So, even though they might comprehend the term 'medical tourism,' but there is no assurance that the sample would consider the options chosen had they been a medical tourist before. In other words, if the sample becomes immediate customers of medical tourism, they might focus on a variety of different factors, which they might not have considered for this study.

\section{Conclusions}

Medical tourism is a growing phenomenon that will con- tinue to spread its charm on the health-care industry. One of the major reasons that will desire patients to travel abroad, especially from a developed country to a developing country would be the skyrocketing costs of medical treatments. Additionally, there are various other factors that will contribute to the flow of medical tourism in developing countries: opportunity to vacation, privacy and anonymity, fewer waiting lines, and some procedures that are not offered in developed countries. It will be fascinating to observe the trend set down by the next generation of medical tourist and the factors that they might consider more important than others. For example, online research was one of the major tools used for searching information on medical tourism, and it might continue to grow importance by the potential medical patients who will consider travelling in near future.

Despite the opportunities and growth of medical tourism industry, there are few limitations that have resulted in comprehension of medical travelers. Some of them are lack of primary knowledge, health insurance companies does not cover all costs, weak malpractice laws in developing countries, hindrances to obtain follow-up care, and outbreak of disease and rebellious attacks. Besides, if the medical procedure needs to be taken care of immediately, then some of these limitations might not apply in those cases. If the medical treatment is very intrusive, then cost might be the main determinant of the visit; however, if less intrusive medical procedure needs to be done then some of the limitations will be brought to sur- 
face. In other words, types of procedures will determine the tourists' willingness of focusing more in support of medical tourism or not.

Additionally, medical tourism needs to be explored further to learn about its significance and importance, and any changes in future demand. It would be helpful if additional research was conducted on this topic, as it would give an opportunity to share and learn from other's insights. Most prominently it will be interesting to explore perceptions of actual medical tourists. For example, which factors they considered more important than others, and also the reasoning behind their choices. Other important aspect would be their experiences with follow-up care. Although learning a topic provides an opportunity to critically think about related issues, but making the actual decision needs more preparation. Moreover, it will be exciting to compare and contrast between the choices made by actual medical tourists as opposed to potential medical tourist. It would give an indepth understanding of the rationale that goes behind decision making process.

This study mainly focused on potential medical tourists and factors that they considered important before travelling out of the US. Many factors were explored to get a glimpse of what could potentially be the medical tourism market: sources to seek medical advice, important considerations before seeking medical care outside the US, choice of destination country, considerations before choosing the destination outside the US, and tools used for researching information on medical tourism. The outcomes from the above questions will give a good understanding of the shift in demand among current and potential medical tourists. The results could be beneficial for businesses that are operating in health-care and tourism related industries, by incorporating the needs of the market.

\section{REFERENCES}

[1] J. Connell, "Medical Tourism: Sea, Sun, Sand and ‥ Surgery,” Tourism Management, Vol. 27, No. 6, 2006, pp. 1093-1100. doi:10.1016/j.tourman.2005.11.005

[2] A. Milstein and M. Smith, "America's New RefugeesSeeking Affordable Surgery Offshore,” New England Journal of Medicine, Vol. 355, No. 6, 2006, pp. 1637-1640. doi:10.1056/NEJMp068190

[3] N. MacReady, "Developing Countries Court Medical Tourists," The Lancet, Vol. 369, No. 9576, 2007, pp. 1849-1850. doi:10.1016/S0140-6736(07)60833-2

[4] M. Mitka, "Surgical Tourism: Some US Patients Travel Abroad for Less Costly Surgery," Journal of the American Medical Association, Vol. 302, No. 14, 2009, pp. 1508-1581. doi:10.1001/jama.2009.1454

[5] D. M. Herrick, "Medical Tourism: Global Competition in
Health Care,” National Center for Policy Analysis, 1 November 2007. http://www.ncpa.org/pub/st304

[6] H. Mueller and E. L. Kaufmann, "Wellness Tourism: Market Analysis of a Special Health Tourism Segment and Implications for the Hotel Industry," Journal of Vacation Marketing, Vol. 7, No. 1, 2001, pp. 15-17. doi:10.1177/135676670100700101

[7] M. Z. Bookman and K. R. Bookman, "Medical Tourism in Developing Countries,” Palgrave Macmillan, New York, 2007. doi:10.1057/9780230605657

[8] K. Ross, "Health Tourism: An Overview," Hospitality Sales and Marketing Association International Marketing Review, 2001.

[9] M. Garcia-Altes, "The Development of Health Tourism Services,” Annals of Tourism Research, Vol. 32, No. 1, 2005, pp. 262-266. doi:10.1016/j.annals.2004.05.007

[10] S. Reddy, V. York and L. Brannon, "Travel for Treatment: Students' Perspective on Medical Tourism,” International Journal of Tourism Research, Vol. 12, No. 5, 2010, p. 510.

[11] J. B. Xu, "Perceptions of Tourism Products," Tourism Management, Vol. 31, No. 5, 2010, pp. 6.7-610. doi:10.1016/j.tourman.2009.06.011

[12] Davidson, "Make Money on Medical Tourism," Forbes.com, 7 December 2007.

http://www.forbes.com/2007/12/07/medical-tourism-emerg ing-pf-ii_ad_1207money_inl.html

[13] P. Oyewole, "Prospects for Developing Country Exports of Services to the Year 2010: Projections and Public Policy Implications,” Journal of Macromarketing, Vol. 21, No. 1, 2001, pp. 32-46.

[14] N. Hanna, "Informatics and the Developing World," Finance and Development, Vol. 28, No. 4, 1991, pp. 45-51. doi:10.1177/0276146701211004

[15] D. Hancock, The Complete Medical Tourist,” John Blake Publishing, London, 2006.

[16] K. Pickert, “Medical Tourism,” Times, 25 November 2008.

http://www.time.com/time/health/article/0,8599,1861919, 00.html

[17] J. Bauer, "Medical Tourism Wave of the Future in a World of Hurt?" Healthcare Financial Management, Vol. 63, No. 8, 2009, pp. 36-38, 40, 42.

[18] M. D. Horowitz and J. A. Rosensweig, "Medical Tourism-Health Care in the Global Economy," The Physician Executive, Vol. 33, No. 6, 2007, pp. 28-30.

[19] Asian Pacific Post, "Sun, Sand and Surgery," 5 May 2005.

[20] S. Reier, "Medical Tourism: Borders Hopping for Cheaper and Faster Care Gains Converts,” International Herald Tribune, 24 April 2004.

[21] O. Analytica, “'Medical tourism’ industry grows rapidly,” 26 October 2006, Forbes.com. http://www.forbes.com/2006/10/25/health-medical-touris m-biz-cx_1026oxford.html

[22] C. G. Lee, "Health Care and Tourism: Evidence from 
Singapore,” Tourism Management, Vol. 31, No. 4, 2010, pp. 486-488. doi:10.1016/j.tourman.2009.05.002

[23] Weaver, “'Passports to Pleasure': Credit Cards and Contemporary Travel," International Journal of Tourism Research, Vol. 7, No. 3, 2005, pp. 151-159.

[24] E. Marnburg, “'I Hope It Won’t Happen to Me!’ Hospitality and Tourism Students' Fear of Difficult Moral Situations as Managers,” Tourism Management, Vol. 27, No. 4, 2006, pp. 561-575. doi:10.1016/j.tourman.2005.02.001

[25] M. Tutton, "Medical tourism: have illness, will travel," CNN Health, 29 March 2009.

http://www.cnn.com/2009/HEALTH/03/26/medical.touris $\mathrm{m} /$ index.html?iref=allsearch\#cnnSTCText

[26] J. McKinley, “A Tax on Nips and Tucks Angers Patients,
Surgeons,” New York Times, 30 November 2009, p. A14.

[27] J. Woodman, "Patients beyond Borders: Everybody's Guide to Affordable, World-Class Medical Tourism," Healthy Travel Media, Chapel Hill, 2007.

[28] P. Mason, P. Grabowski and W. Du, "Severe Acute Respiratory Syndrome, Tourism and the Media," The International Journal of Tourism Research, Vol. 7, No. 1, 2005, pp. 11-21. doi:10.1002/jtr.519

[29] R. Law, "The Perceived Impact of Risks on Travel Decisions,” International Journal of Tourism Research, Vol. 8, No. 4, 2006, pp. 289-300. doi:10.1002/jtr.576

[30] N. Singh and M. J. Lee, "Exploring Perceptions toward Education in 3-d Virtual Environments: An Introduction to 'Second Life'," Journal of Teaching in Travel \& Tourism, Vol. 8, No. 4, 2008, pp. 315-327. 